\title{
TRADUÇÃO DE CONVERSIÓN DE PIRITU (EXCERTOS), DE RUIZ BLANCO, PARA O PORTUGUÊS BRASILEIRO: O COMENTÁRIO DA TRADUÇÃO COMO EXPERIÊNCIA METALINGUÍSTICA
}

\author{
Joaquim Martins Cancela Júnior ${ }^{1}$ \\ 1Universidade Federal do Pará-Soure, Soure, Pará, Brasil \\ Lilian Cristina Barata Pereira Nascimento 2 \\ ²Universidade Federal do Pará-IEMC, Belém, Pará, Brasil
}

$\mathrm{Na}$ atual Venezuela, nos estados de Anzoátegui, Sucre e Monagas, Matías Ruiz Blanco (1643 - 1708), frei franciscano da Ordem dos Frades Menores (OFM), natural de Sevilha (Espanha), atuou como missionário nas regiões de Piritu e Cumaná, essas que integravam a Província Nova Andaluzia, fundada por Diego Hernández de Serpa, em 1568, e mais tarde governada pelo catalão Joan Urpín, ao estabelecer a Província Nova Catalunha, em 1633.

Com apenas 27 anos, Ruiz Blanco se inscreveu na terceira expedição franciscana para atuar na missão venezuelana de Piritu. No período que esteve em missão, de 1672 a 1708, o frei aprendeu a língua cumanagota, fundou povoados, catequizou povos indígenas (Cumanagotos, Palenques e Chaima, principalmente), instruiu religiosos catequistas, escreveu livros, gramática e dicionário bilíngue em língua espanhola e cumanagota, além de tradução de textos católicos em latim e/ou espanhol para cumanagoto, e fez comentários de suas traduções. Nesse mesmo período, Ruiz Blanco retornou à Espanha algumas vezes para resolver questões ligadas às missões e às publicações de seus livros. 
O topônimo Piritu estava relacionado ao porto da região, atual cidade Puerto Piritu - Venezuela, onde o fluxo de pessoas e mercadorias era intenso, e também, onde se encontrava o maior número de falantes da língua cumanagota, possível língua geral da região (Cernuda).

Atualmente a língua cumanagota, do tronco linguístico caribe, está extinta, o que hoje existe dela se encontra somente nos registros escritos de missionários franciscanos, principalmente os do período colonial. O que aconteceu com ela foi o mesmo que ocorreu com as muitas línguas ameríndias, sofreu um longo e complexo processo no desaparecimento da língua ancestral, que a partir de uma visão sociolinguística pode estar relacionado à mudança sociocultural e a transculturação, provenientes de sucessivas violências do período colonial, seja de forma física ou simbólica, pois o desaparecimento de uma língua e/ou a substituição da língua indígena por línguas europeias (no caso da colonização na América) gera o aparecimento de populações que são definidas de forma generalizada, como indígenas genéricos, trabalhadores do campo, caboclos, etc.; sem contar o sentimento de vergonha étnica e linguística principalmente entre os indígenas mais jovens, gerado pela transculturação compulsiva, uma forma de etnocídio. (Castillo).

A obra Conversión de Piritu, de Ruiz Blanco, foi publicada em 1690, em Madri, pela Juan García Infançon. Em 1892, foi publicada a $2^{a}$ edição pela Librería de Victoriano Suarez, também em Madri, com a ortografia atualizada e pequenas modificações no texto. E em 1965, publicada a $3^{a}$ edição, pela Biblioteca de la Academia Nacional de la Historia, em Caracas, que novamente teve a ortografia atualizada.

De acordo com Cernuda (2014) Conversión de Piritu é uma obra poliedra, pois apresenta cinco faces: uma introdução histórica (corográfica e etnográfica) da região, textos católicos traduzidos e comentados seguindo o princípio tradutório de São Jerônimo, os mandamentos e os preceitos da Santa Igreja em cumanagoto, uma gramática da língua cumanagota e um dicionário bilingue espanhol - cumanagoto.

Utilizamos a $1^{\text {a }}$ edição, de 1690 , como texto-fonte na presente tradução para o português brasileiro de Conversión de Piritu (121 
- 137) excertos da segunda parte Práctica que hay en la enseñanza de los indios, y un directivo para que los religiosos puedan cómodamente instruirlos en las cosas esenciales de la religión cristiana (cap. II, III, IV e V), pois encontramos significativas mudanças em relação às edições posteriores. O exemplo mais aparente está no início do capítulo II, no parágrafo 13, quando a edição de 1690 inicia com Supongo (121), e a edição de 1892 muda para Advierto (169). No entanto, no parágrafo 15, o autor inicia com Supongo también $(1690,122 ; 1892,170)$ nas duas edições, sugerindo a continuação da "suposição" sobre a tradução de textos católicos para a língua cumanagota.

Essa segunda parte do livro, sobre a prática que há no ensino dos indígenas, inicia com os nomes dos frades que autorizaram a publicação e o ano da autorização (1688), seguida dos motivos da obra, estes direcionados ao leitor. O capítulo I inicia com a explicação sobre Persignar-se, ou seja, gestos do sinal da cruz feitos três vezes (na testa, na boca e no peito), as orações (Pai Nosso, Ave Maria, Credo), Símbolo da Fé etc., tudo escrito em língua cumanagota, ou seja, a tradução em língua indígena como porta de entrada, os únicos escritos em espanhol são os títulos das orações.

Do $2^{\circ}$ ao $5^{\circ}$ capítulo (a tradução propriamente dita deste trabalho para o português brasileiro), Ruiz Blanco apresenta os seus comentários da tradução, justificando suas escolhas tradutórias, seguindo a mesma prática tradutória de São Jerônimo (347 - 420) ao traduzir a Bíblia para o latim (Vulgata), fazendo referência ao texto Óptimo Genere Interpretandi - Ad Pammachium, Epistula LVII (396), pois o franciscano espanhol seguia o princípio ad sensum, a partir do sentido da frase completa e não ad literam, que é a tradução de palavra por palavra, visto que ele se preocupava com o princípio de equivalência linguística ao traduzir os textos católicos para a língua cumanagota, na tentativa de recuperar o significado de toda a frase (Sarion). Assim inicia seu comentário de tradução no capítulo II parágrafo $13(1690,121)$ : 
13. Supongo que en esta traducción he procurado interpretar las voces del idioma Castellano, de que inútilmente se ha usado hasta aquí, con otras del idioma de los Indios, propias, $o$ equivalentes en el sentido, y que explican muy bien lo sustancial de los misterios, en que es necesario sean instruidos; porque según notó San Gerónimo de optim. gen. interprot. en las versiones, no tanto se ha de atender a lo material de las voces, cuanto a su formal significación, y sentido: y supuesto que en el nativo lenguaje hay voces con las cuales se les puede dar a entender los divinos misterios, e instruirlos en lo que deben creer, es cosa irracional entender, que con términos, y voces del idioma Castellano, que no saben, ni entienden, puedan venir en conocimiento de lo que se les dice, y promulga.
13. Suponho que nesta tradução procurei interpretar as vozes do idioma Espanhol, que inutilmente se usou até aqui, com outras do idioma dos Indígenas, próprias ou equivalentes no sentido, e que explicam muito bem o essencial dos mistérios, sendo necessário que sejam instruídos; porque segundo observou São Jerônimo nas versões de optm. gen. interproet., nem tanto atende ao material das vozes, quanto a sua significação formal e sentido: e claro que na língua nativa há vozes com as quais se pode entender os mistérios divinos e instruir-lhes no que devem crer, é coisa irracional entender, que com expressões e vozes do idioma Espanhol, que não sabem, nem entendem, possam vir a conhecer aquilo que lhes é dito e promulgado.

Outra perspectiva de tradução de textos católicos no final do século XVII, que muitos missionários adotavam era o princípio de tradução ciceroniano, fazendo referência ao prefácio De Optimo Genere Oratorum, de 46 a.C., texto que Cícero (106 a.C. - 43 a.C.) reflete sobre o estilo retórico e a tradução (Sarion), defendendo uma tradução mais livre, ao afirmar que prefere traduzir como um orador.

Há também nos comentários de tradução, de Ruiz Blanco, referência ao Terceiro Concílio Limenho (1583 - 1584), Epístola sobre a tradução da Doutrina Cristã, que decretou:

[...] hacerse por nuestra orden y comisión una traducción auténtica del catecismo y Doctrina Cristiana, que todos sigan. [...] Pareció a este sancto Concilio Provincial proveer y mandar con rigor que ninguno use otra traducción, ni enmiende ni añada en ésta cosa alguna; porque, aunque hu- 
biese cosas que por ventura se pudiesen decir mejor de otra suerte (que forzoso es que haya siempre en esto de traducción diversas opiniones), pero hace juzgado, y lo es menos inconveniente, que se pase por alguna menos perfección que tenga por ventura la traducción, que no dar lugar a que haya variedad y discordias, como en las traducciones de la Santa Escritura saludablemente lo ha proveído la Iglesia Católica. (1583, 17 - 18)

Ruiz Blanco era contrário à política linguística e tradutória decretada pelo supracitado Concílio, não reconhecia como válido na tradução para a língua indígena o empréstimo de palavras espanholas, neologismos ou a tradução palavra por palavra, como vemos nos parágrafos 16 e 17 (122 - 123):

16. Mas no obstante que estos supuestos son tan evidentes, podrá replicar alguno, y decir, que en uno de los Concilios Limenses hay precepto para que en la traducción de la Doctrina Cristiana, cuando falten términos de los lenguajes de los Indios, se suplan con otros de la lengua Castellana: luego no obsta la interposición de voces Castellanas con las de cualquier otro idioma de los Indios.

17. Respondo, que el precepto del Concilio tiene, en caso que en cualquiera idioma no se hallen términos formales, o equivalentes con que traducir, o explicar los misterios, y demás cosas tocantes a la Doctrina Cristiana, y así aunque no es obstáculo, en caso que no se
16. Mas, a pesar dessas suposições serem muito evidentes, alguns podem questionar, e dizer que num dos Concílios Limenho há um preceito sobre a tradução da Doutrina Cristã, que quando faltem expressões da língua dos Indígenas, se supram com outras da língua Espanhola: logo não impede a interposição de vozes Espanholas com as de qualquer outro idioma dos Indígenas.

17. Repito, que o preceito do Concílio tem, em qualquer idioma, no caso de não encontrar expressões formais ou equivalentes para traduzir ou explicar os mistérios, e demais coisas a respeito da Doutrina Cristã, e mesmo sem dificuldade, no caso de não encontrem outras, com 
hallen otros, con ellos nunca se elas nunca poderá conseguir que podrá conseguir el que entiendan entendam os mistérios da Fé, que los misterios de la $\mathrm{Fe}$, lo cual es são alheios à dúvida.

ajeno de duda.

É importante trazer as referências teóricas do tradutor, para conhecermos melhor a concepção de tradução de Ruiz Blanco. Seguindo a perspectiva teórica de José Lambert:

[...] nos importa, em primeiro lugar, determinar a concepção das traduções num momento determinado da história. A tradução se torna assunto de estudo; procura-se saber quem produz as traduções, para que público, com o auxílio de que textos, em que gêneros, em que línguas e linguagem, segundo que registros e esquemas literários, em função de que modos literários, morais, linguísticos, políticos; e ademais, em função de que concepção de tradução. (Lambert, 196).

A obra Conversión de Piritu estava direcionada aos religiosos catequistas, para que pudessem ter mais conhecimento e prática na língua cumanagota, através da gramática e do dicionário bilíngue, e que conhecessem as orações e os mistérios divinos em língua nativa. Bastin, Pantin e Duoara (2013) destacam o modo de traduzir, de Ruiz Blanco, que mesmo apresentando as dificuldades de comunicação com os indígenas de Piritu, traduz, retraduz e analisa seu processo tradutório, já que seu texto tem caráter filológico pelo grande número de comentários linguístico. Como um autêntico tradutor-autor, Ruiz Blanco "produz um outro texto - apesar de carregar a marca da identidade do texto original -, o texto traduzido transformado em energia criativa. O tradutor é, portanto, um autor" (Torres, 133).

Recorremos também a análises de outros elementos que julgamos centrais no processo tradutório, a maior parte deles, inclusive, ressaltados mesmo por Ruiz Blanco, já que seu próprio texto se trata, na 
verdade, de uma tradução comentada, como já mencionamos. Uma das principais dificuldades encontradas por ele estava relacionada a encontrar no idioma nativo um termo que desse conta, ao mesmo tempo, da ideia de entendimento e aceitação. Como veremos a seguir, havia inicialmente três possibilidades tradutórias para esse fim.

25. La primera decía: ure yehua man Dios; la segunda: yehua mana tehui quene Dios mana quaneren; la tercera: ycatemaze Dios pueque; la primera no declara más que, yo sé; porque la palabra Dios, no la entendían los Indios; la segunda declara: sé que hay uno sólo de verdad; la tercera decía: tengo gusto o complacencia; de las cuales consta, que aunque los Indios entendieran la partícula Dios, se infiere, que sólo podían hacer estos actos, se, o conozco que hay un Dios, o conozco que hay un Dios verdaderamente; $\mathrm{y}$ finalmente tengo gusto o complacencia en Dios, porque la palabra yechuamana, según su verdadera significación, no es otra cosa que conozco o sé; y la palabra ycatemaze, no significa otra cosa, que gustar o tener complacencia, y en todo rigor sólo significa gustar con el paladar.
25. A primeira dizia: ure yehia man Dios; a segunda: yehua, man tehui quene Dios mana quaneren; a terceira: Ycatemaze Dios pueque; a primeira não revela mais que eu sei; porque a palavra Deus, os indígenas não a entendiam; a segunda revela: Sei que há uma só verdade; a terceira dizia: tenho gosto ou condescendência; do qual consiste que, embora os indígenas entendessem a partícula Deus, inferese que só podiam fazer esses atos se, eu conheço que há um Deus, ou com toda a verdade eu conheço que há um Deus; e finalmente tenho gosto ou condescendência em Deus, porque a palavra yechuamana, segundo seu real significado, não é outra coisa que conheço ou sei; e a palavra ycatemaze não significa outra coisa senão gostar ou ter condescendência, e com todo rigor, significa apenas sentir com o paladar.

Pelas razões por ele mesmo descritas, nenhuma das acepções em destaque eram adequadas o suficiente para indicar o assenso do entendimento. A primeira ocorrência indica um conhecimento muito superficial, a simples noção de tomar ciência da existência. A segunda possibilidade até inclui a ideia de entender de que Deus seria a única verdade enquanto informação, mas ainda sem o comprometi- 
mento pessoal acerca dela. Ora, mesmo um ateu convicto que tenha algum conhecimento histórico dificilmente negará a existência de Jesus enquanto ser humano, por exemplo, e mesmo algumas religiões sabem de sua existência, mas não o veem da mesma maneira como o catolicismo. E finalmente a terceira acepção ficava ainda mais distante do propósito almejado por Ruiz Blanco, pois indicava simplesmente um conhecimento sensorial, mais relacionado ao paladar.

Mais à frente, Ruiz Blanco finalmente indica duas possibilidades para traduzir este assenso de entendimento: ymoromaze e huecmaze a que chamou de "a margarida escondida" e chegou até elas após ter reunido "os Indígenas mais capazes e intérpretes de maior satisfação" $(1690,132)$. Sobre estes últimos, não podemos esquecer as motivações do documento que traduzimos: Ruiz Blanco comenta a tradução do Símbolo da Fé com o objetivo de tornar a evangelização mais eficaz e acaba produzindo como que um manual catequético para futuros missionários de Piritu e Cumaná. Em alguns trechos de seu texto podemos ver que ele já compreende, inclusive, a importância de considerar também aspectos culturais. Vejamos:

42. [...] Hubo un Religioso Lego en esta conversión, llamado Fr. Juan Villegas, que era un bendito varón y al parecer inepto y muy tosco; éste con la costumbre de andar con los Indios en el monte y en las demás funciones que se ofrecían, llegó a comprender tanto el lenguaje de dichos Indios, que no se diferenciaba de ellos cuando hablaba. [...]
42. [...] Houve um Religioso Leigo nesta conversão, chamado Fr. Juan Villegas, que era um varão abençoado, e de aparência inapta e muito tosca; este, com o costume de andar com os Indígenas no monte e nas demais funções que o ofereciam, chegou a compreender tanto a língua dos referidos Indígenas que não se diferenciava deles quando falava. [...]

Mesmo que ainda de forma mais empírica e não necessariamente preocupado com a cultura local, Ruiz Blanco já vislumbra os efeitos da aproximação cultural no comportamento de alguns catequistas. No caso citado, o religioso chega mesmo a se confundir 
com os indígenas, tendo se inserido no dia a dia da comunidade e reproduzindo outras dimensões da sua realidade, além da própria linguagem. Severi e Hanks (2014) compreendem a tradução como um fenômeno multidimensional no qual a linguagem é o elemento central. Ao mesmo tempo apontam uma série de outros fatores como camadas de informações complementares que podem vir da troca de valores, teorias e, inclusive, aproximações que envolvem conversão religiosa. De maneira semelhante, Lloyd (2014) vê a própria realidade como sendo multidimensional e define a tradução como uma questão de inteligibilidade mútua a partir de diversos registros. Ruiz Blanco tinha tanta certeza desta importância que para ilustrar seu entendimento chega mesmo a declarar que utilizar o idioma espanhol no processo de catequese seria "o mesmo que falar com surdos" $(1690,133)$.

O que denominamos no subtítulo o comentário da tradução como experiência metalinguística faz alusão ao espelhamento do exercício ao comentar a tradução. No ato de traduzir os comentários de tradução de Ruiz Blanco para o português brasileiro, fizemos o mesmo exercício ao comentar nossas escolhas tradutórias e analisar as dele, ou seja, uma experiência metalinguística, pois a questão não é sobre tecer quaisquer comentários, mas reconhecer que esses comentários são poderosos recursos da língua que o falante experimenta ao falar dela e sobre ela (Flores).

Quando reconhecemos a tradução como objeto da metalinguagem, estamos tratando do exercício metalinguístico do traduzir, pois o comentário da tradução já é uma metalinguagem da metalinguagem; e a experiência se multiplicou quando fizemos a tradução de um comentário de tradução seguido de outro comentário de tradução, nesse caso estamos falando da metalinguagem como experiência metalinguística (Flores). 


\section{Referências}

Bastin, Georges; Pantin, Jeanette; Duoara, Nawaf. Los franciscanos y la traducción en Venezuela, 2013. http://www.traduccion-franciscanos.uva.es/ archivos/5.Bastin.Venezuela.pdf. Acesso em 05 de outubro de 2020.

Blanco, Matías Ruiz. Conversion de Piritu. De indios cumanagotos, palenques, y otros: Sus principios, y incrementos que oy tiene, con todas las cosas mas singulares del pais, politica, y ritos de sus naturales, practica que se observa en su reduccion, y otras cosas dignas de memoria. Madri: Juan García Infançon, 1690. Biblioteca online John Carter Brown: https://archive.org/details/ conversiondepiri00ruiz/page/n155/mode/2up. Acesso em 10 de outubro de 2020.

Blanco, Matías Ruiz. Conversión en Piritú (Colombia) de indios cumanagotos y palenques con la práctica que se observa en la enseñanza de los naturales en lengua cumanagota. Madri: Librería de Victoriano Suarez, 1892. Biblioteca Digital Hispánica: http://bdh.bne.es/bnesearch/CompleteSearch.do?showYearIte $\mathrm{ms}=\&$ field $=$ todos\&advanced $=$ false \&exact $=$ on\&textH $=\&$ completeText $=\&$ tex $\mathrm{t}=$ mat $\% \mathrm{c} 3 \%$ adas + ruiz + blanco\&language View $=$ es\&pageSize $=1 \&$ pageSizeAb $\mathrm{rv}=30 \&$ pageNumber $=2$. Acesso em 08 de novembro de 2020 .

Blanco, Matías Ruiz. Conversión de Piritu. Serie Fuentes para la Historia Colonial de Venezuela, vol. 78. Caracas: Academia Nacional de la Historia, 1965.

Castillo, Horacio Biord. "El (re) aprendizaje de una lengua extinta: etnogénesis entre los Cumanagotos del nororiente de Venezuela". Revista Antropología Americana, v.3, $\mathrm{n}^{\circ} 6$, (2018): 35-55: https://www.revistasipgh.org/index.php/ anam/article/view/129. Acesso em 05 de janeiro de 2021.

Cernuda, Miguel Ángel Vega. "La convención de Piritú de Matías Ruiz Blanco, un texto híbrido de língüística, traducción y etnografía”. Revista In-Traduções, v. 6, (2014): 155-170. http://stat.necat.incubadora.ufsc.br/index.php/intraducoes/ article/view/2770/3301. Acesso em 08 de outubro de 2020. 
Doctrina christiana, y catecismo para instruccion de los indios, y de las de mas personas, que han de ser enseñadas en nuestra sancta fé: Con un confessionario, y otras cosas necessarias para los que doctrinan, que se contienen en la pagina siguiente. Ciudad de los Reyes: Antonio Ricardo,1584. Biblioteca Digital Hispánica: http://bdh-rd.bne.es/viewer.vm?id=0000192416\&page=1. Acesso em 11 de dezembro de 2020.

Flores, Valdir do Nascimento. "A condição tradutória". Problemas gerais de linguística. Rio de Janeiro: Vozes, 2019.

Lambert, José. "A tradução". Tradução de Marie-Hélène Catherine Torres e Álvaro Faleiros. Literatura e Tradução: textos selecionados de José Lambert. Rio de Janeiro: 7 letras, 2011.

Lloyd, Geoffrey. "On the very possibility of mutual intelligiblity". Journal of Ethnographic Theory, v. 4, $\mathrm{n}^{\circ}$ 2, (2014): 221-235. http://www.haujournal.org/in dex.php/hau/issue/view/hau4.2. Acesso em 18 de novembro de 2020.

Sarion, Roxana. "Teología de la traducción. Estrategias de adaptación lingüística en los catecismos de la provincia de Cumaná en Venezuela (siglo XVII)". Lingüística misionera: aspectos lingüísticos, discursivos, filológicos y pedagógicos. Lima: Fondo Editorial de la Pontificia Universidad Católica del Perú, 2019. https:// munin.uit.no/handle/10037/18463. Acesso em 07 de outubro de 2020.

Sarion, Roxana. Translator proditor. The affirmation of the authorial voice in Matías Ruiz Blanco. https://hiphilangsci.net/2015/09/30/translator-proditorthe-affirmation-of-the-authorial-voice-in-matias-ruiz-blanco/. Acesso em 07 de outubro de 2020.

Severi, Carlo; Hanks, William. "Translating Worlds: The epistemological space of translation". Journal of Ethnographic Theory, v. 4, no 2, (2014): 1-16. http://www.haujournal.org/index.php/hau/issue/view/hau4.2. Acesso em $12 \mathrm{de}$ novembro de 2020. 
Torres, Marie-Hélène Catherine. "O tradutor: perfil e análise". No horizonte do provável: ensaios sobre tradução. Rio de Janeiro: 7 Letras, 2013.

Joaquim Martins Cancela Júnior. E-mail: jmcj.ufpa@gmail.com. https://orcid. org/0000-0002-5568-5524.

Lilian Cristina Barata Pereira Nascimento. E-mail: sralilian@gmail.com. https:// orcid.org/0000-0003-3587-849X. 